\title{
Article \\ Mechanical Properties of Hybrid Structures Incorporating Nano-Silica and Basalt Fiber Pellets
}

\author{
Ahmed Bediwy ${ }^{1}$ and Ehab F. El-Salakawy ${ }^{2, *(D)}$ \\ 1 Department of Civil Engineering, University of British Columbia, Vancouver, BC V6T 1Z4, Canada; \\ ahmed.bediwy@ubc.ca \\ 2 Department of Civil Engineering, University of Manitoba, Winnipeg, MB R3T 2N2, Canada \\ * Correspondence: ehab.el-salakawy@umanitoba.ca
}

Citation: Bediwy, A.; El-Salakawy, E.F. Mechanical Properties of Hybrid Structures Incorporating Nano-Silica and Basalt Fiber Pellets. CivilEng 2021, 2, 909-928. https://doi.org/ 10.3390/civileng2040049

Academic Editor: Angelo Luongo

Received: 15 September 2021

Accepted: 10 October 2021

Published: 14 October 2021

Publisher's Note: MDPI stays neutral with regard to jurisdictional claims in published maps and institutional affiliations.

Copyright: (c) 2021 by the authors. Licensee MDPI, Basel, Switzerland. This article is an open access article distributed under the terms and conditions of the Creative Commons Attribution (CC BY) license (https:/ / creativecommons.org/licenses/by/ $4.0 /)$.

\begin{abstract}
Recently, developing a nonferrous reinforcement system (corrosion-free system) using durable and ductile cement-based materials that incorporate discrete fibers has been a promising option for exposed concrete structures in cold regions or marine environments. Therefore, in this study, properties of a novel type of cementitious composite comprising nano-silica and a high dosage of slag were investigated. The hybrid (layered) composites assessed in this study were composed of two layers of different types of cementitious composites. Normal concrete (NC) was used in the top layer combined with a layer of fiber-reinforced cementitious composite (FRCC) reinforced with either the recently developed basalt fiber $(\mathrm{BF})$ pellets (basalt fiber strands encapsulated by a polymeric resin or steel fibers (SF)) that were used at different dosages. The post-cracking behavior in terms of residual strength, residual index, and toughness are presented and discussed. The analysis of results showed the effectiveness of the BF pellets in enhancing the post-cracking behavior of specimens, as they behaved comparably to counterpart specimens comprising SF, which makes them a good candidate for infrastructural applications including rehabilitation such as new bridge girders or overlays.
\end{abstract}

Keywords: basalt fiber pellets; fiber-reinforced cementitious composites; nano-silica; layered concrete structures; post-cracking behavior; slag; steel fibers

\section{Introduction}

Concrete often cracks due to its limited tensile and deformation capacity. The presence of cracks may not only affect the aesthetics of structures, but also its durability by allowing the infiltration of moisture and oxygen causing corrosion of the reinforcing steel accompanied by a deterioration of the concrete [1]. In addition, the presence of de-icing salts and repeated freezing-thawing cycles in cold regions aggravate the damage of concrete. Therefore, to expand the possibilities of using concrete in such harsh environments, developing high performance mortar/composite and concrete to rehabilitate concrete infrastructure (e.g., bridge decks, pavements, parking structures) is much needed [2].

In this context, the use of a fiber-reinforced cementitious composite (FRCC) has been suggested by many researchers to enhance short-term structural performance. Incorporating discrete fibers into any cementitious composite (e.g., geopolymer mortar) can reduce bleeding, controlling shrinkage cracking, and improving impact resistance [3]. Furthermore, the most pronounced advantages of using fibers in cementitious composites are increasing their energy absorbing capacity, deformation capability, and load bearing capacity after cracking due to the ability of the fibers to bridge cracks and to transfer tensile stress across the crack interface [4]. In addition, incorporating waste materials along with short fibers significantly enhanced the mechanical properties [5].

The application of discrete fibers mainly contributes to the improvement of FRCC tensile properties [6]. However, previous studies showed that the contribution of fibers in enhancing the compressive strength is insignificant. Accordingly, it is reasonable and 
more on economical to implement fibers in structural members on the tension side only to cast layered (hybrid) structures. For example, a simply supported beam under flexural service loads is subjected to tension on the bottom side and compression on the top side. Applying the FRCC as a layer in the tension side of such a beam could significantly improve the post-cracking flexural capacity, while using the fibers in the compression zone would contribute less [7].

Various commercially available fibers can be used to make fiber-reinforced cementitious composites, such as steel and synthetic, organic, and inorganic fibers. However, relatively new types of fibers manufactured from basalt rocks are progressively emerging in civil engineering research, including a special type of basalt fiber (BF) pellets, which are made of basalt fibers encapsulated by polyamide or other resins. The production process of basalt fibers is more environmentally friendly, and it is cheaper in comparison to other types of fibers such as glass fibers. In addition, basalt fibers have high tensile strength, and they are not vulnerable to corrosion in contrast to the corrodible steel fibers that result in rough concrete surfaces, which should be avoided in applications such as slabs on the ground, bridge decks, and pavements [8-12].

Despite the advantages of fibers, it was reported that adding fibers in mortar or concrete may increase its permeability due to the formation of numerous weak interfacial transition zones (ITZ) between the fibers and cementitious matrix. In addition, the efficacy of fiber reinforcement depends upon the matrix composition [4,13-16].

Therefore, producing a cementitious composite with superior properties is crucial, which can be obtained by incorporating supplementary cementitious materials (SCMs), such as silica fume and/or ground granulated blast-furnace slag. These supplementary materials can react with calcium hydroxide crystals, the weakest by-product of the cement hydration reaction, to form more calcium silicate hydrate $(\mathrm{CSH})$, which is the backbone of concrete strength and binding. This results in a refined and denser microstructure and ITZ. Nevertheless, it is worth noting that slag is a latent hydraulic binder which mainly contributes to improving the long-term performance of cementitious systems and incorporating high dosages of slag usually leads to a delay in hardening and strength as well as microstructural development during the early ages [17,18]. In addition, it is well-documented that adding a small dosage of nanoparticles (e.g., nano-silica, NS) can vigorously speed up the kinetics of cement hydration, especially during the early ages, besides their contribution to improving the microstructural development of cement-based materials [17,19-21].

This study presents part of an ongoing program at the University of Manitoba. The first phase of this project was undertaken by Mahmoud et al. [12], who investigated the behavior of high-strength nano-modified cementitious composites incorporating 6\% NS with $40 \%$ slag and reinforced with BF pellets (BFRCC) in terms of compressive strength, flexural strength, and toughness. The slag replacement level (40\%) was selected to meet the requirements of the category HVSCM-2 for high SCM concretes according to CSA A23.1/A23.2-19 (Annex K) [22]. It was concluded that this BFRCC had high performance and potential to be applied in structural applications. Yet, some research gaps and limitations still exist and need to be addressed to fully exploit this innovative composite (BFRCC) in infrastructure applications. For instance, only one dosage of BF pellets was used in the previous study by Mahmoud et al. [12], and the results were not compared with composites incorporating steel fibers (SF), which are currently the most used fibers in the construction industry. In addition, the concept of layered structures (hybrid structures) was not applied. These trends have not been substantiated by systematic research work.

This study provides much better understanding and fundamental data about these composites for achieving improved performance of structural elements incorporating BFRCC. The fresh, hardened, and durability properties of these composites were evaluated. 


\section{Experimental Program}

\subsection{Materials}

General use (GU) cement and slag, which meets the requirements of CSA-A3001 [23], were used as the main components of the binder. Table 1 shows the chemical and physical properties of these main components. In addition, a commercial nano-silica (NS) sol was added in the binder. Fine aggregate, having a fineness modulus of 2.9 and a gradation less than $600 \mu \mathrm{m}$ according to ASTM C136 [24], was adopted to cast the composites. The specific gravity and absorption of the fine aggregate were 2.6 and $1.5 \%$, respectively, according to ASTM C128 [25]. A high-range water-reducing admixture (HRWRA) complying with ASTM C494 Type F [26] was used to target a flow between 185 and $215 \mathrm{~mm}$ for all composites. The cementitious composites were reinforced with either BF pellets or steel fibers (Figure 1). The BF pellets were made of 16-micron basalt roving encapsulated by polyamide resin, and the BF represented $60 \%$ of the pellet by weight. The BF pellets were $36 \mathrm{~mm}$ long with a diameter of $1.8 \mathrm{~mm}$. Hooked-end steel fibers with a diameter of 0.5 and $30 \mathrm{~mm}$ in length were also used. The properties of the BF pellets and the steel fibers are listed in Table 2.

Table 1. Chemical and physical properties of GU cement and slag.

\begin{tabular}{|c|c|c|c|c|c|c|c|c|c|}
\hline \multirow[b]{2}{*}{ Binder } & \multicolumn{7}{|c|}{ Chemical Composition (\%) } & \multicolumn{2}{|c|}{ Physical Properties } \\
\hline & $\mathrm{SiO}_{2}$ & $\mathrm{Al}_{2} \mathrm{O}_{3}$ & $\mathrm{Fe}_{2} \mathrm{O}_{3}$ & $\mathrm{CaO}$ & $\mathrm{MgO}$ & $\mathrm{SO}_{3}$ & $\mathrm{Na}_{2} \mathrm{O}_{\text {eq }}$ & $\begin{array}{l}\text { Blaine } \\
\left(\mathrm{m}^{2} / \mathrm{kg}\right)\end{array}$ & $\begin{array}{l}\text { Specific } \\
\text { Gravity }\end{array}$ \\
\hline Cement & 19.21 & 5.01 & 2.33 & 63.22 & 3.31 & 3.01 & 0.12 & 390 & 3.15 \\
\hline Slag & 33.40 & 13.40 & 0.76 & 42.70 & 5.30 & 2.40 & 0.30 & 492 & 2.87 \\
\hline
\end{tabular}
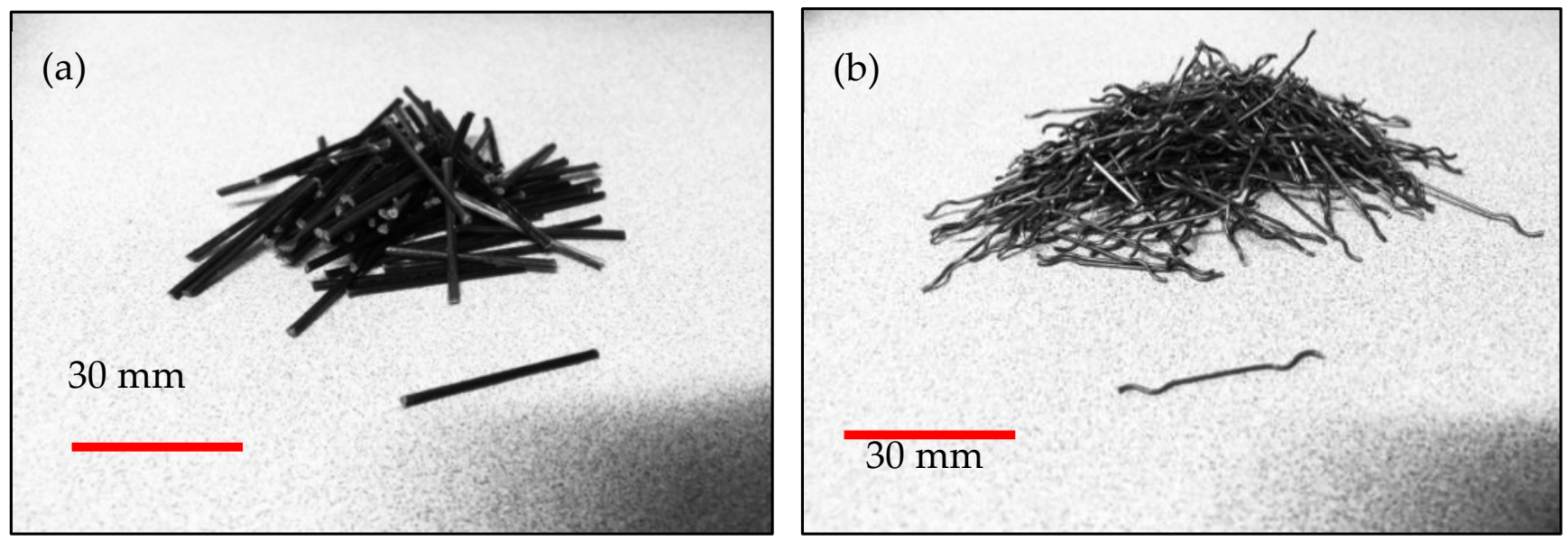

Figure 1. Reinforcing fibers: (a) basalt fiber pellets, and (b) steel fibers.

Table 2. Properties of fibers.

\begin{tabular}{ccc}
\hline \multirow{2}{*}{ Properties } & \multicolumn{2}{c}{ Properties of Fibers } \\
\cline { 2 - 3 } & BF Pellets & Hooked Steel \\
\hline Length $(\mathrm{mm})$ & 36 & 30 \\
Diameter/dimensions $(\mathrm{mm})$ & 1.80 & 0.65 \\
Aspect ratio & 20 & 45 \\
Specific gravity & 1.74 & 7.70 \\
Tensile strength (MPa) & 2300 & 1200 \\
Elastic modulus (GPa) & 65 & 200 \\
\hline
\end{tabular}




\subsection{Proportions and Mixing Procedues}

For the FRCC layer on the tension face of the specimens, two mixtures were cast: normal cementitious composite (designated as $\mathrm{N}$ ) and high-performance cementitious composite (designated as $\mathrm{H}$ ). Further description of the components of the $\mathrm{N}$ and $\mathrm{H}$ mixtures can be found elsewhere [27]. The mixtures were reinforced with BF pellets and $\mathrm{SF}$. The rationale to select the dosages of fiber is illustrated by the authors elsewhere. The reference composite was cast with the same ingredients but without fibers. Table 3 shows the proportions of all mixtures. For the mixture nomenclature, the first letter illustrates the type of the cementitious composite (" $\mathrm{N}$ " for normal mixture and " $\mathrm{H}$ " for high-performance mixture), whereas the second letter refers to the type of fiber (" $\mathrm{B}$ " for basalt fiber pellet and " $S$ " for steel fiber). The third part (number) illustrates the dosage of fibers. The base concrete was cast to satisfy the requirements specified by the City of Winnipeg (COW), Manitoba, Canada, for structural concrete projects. The COW has specified concrete with a target compressive strength of $35 \mathrm{MPa}$ at 28 days meeting an exposure Class $\mathrm{C}-1$ and comprising synthetic fibers with a minimum post-residual cracking index of 0.15 at 7 days.

Table 3. Proportions of the mixtures per cubic meter.

\begin{tabular}{|c|c|c|c|c|c|c|c|c|}
\hline \multirow[b]{2}{*}{ Mixture ID } & \multirow{2}{*}{$\begin{array}{l}\text { Cement } \\
\text { (kg) }\end{array}$} & \multirow[b]{2}{*}{ Slag (kg) } & \multirow{2}{*}{$\begin{array}{c}\text { Water }^{\mathrm{a}} \\
(\mathrm{kg})\end{array}$} & \multirow{2}{*}{$\begin{array}{l}\text { Nano- } \\
\text { Silica } \\
\text { (NS, kg) }\end{array}$} & \multirow{2}{*}{$\begin{array}{c}\text { Fine } \\
\text { Aggregate } \\
\text { (kg) }\end{array}$} & \multirow{2}{*}{$\begin{array}{c}\text { HRWRA ** } \\
\text { (L) }\end{array}$} & \multicolumn{2}{|c|}{ Fibers (kg) } \\
\hline & & & & & & & BF Pellets & $\begin{array}{c}\text { Hooked } \\
\text { Steel }\end{array}$ \\
\hline N-X-0.0 & 700 & - & 210 & - & 1471 & 5.7 & - & - \\
\hline H-X-0.0 & 420 & 280 & 180 & 84 & 1328 & 7.4 & - & - \\
\hline N-B-2.5 & 700 & - & 210 & - & 1406 & 5.7 & 43.3 & - \\
\hline N-B-4.5 & 700 & - & 210 & - & 1354 & 5.7 & 78.3 & \\
\hline N-B-6.9 & 700 & - & 210 & - & 1293 & 5.7 & 119.2 & - \\
\hline N-S-1.0 & 700 & - & 210 & - & 1445 & 5.7 & - & 77 \\
\hline H-B-2.5 & 420 & 280 & 180 & 84 & 1268 & 7.4 & 43.3 & - \\
\hline H-B-4.5 & 420 & 280 & 180 & 84 & 1211 & 7.4 & 78.3 & \\
\hline H-B-6.9 & 420 & 280 & 180 & 84 & 1150 & 7.4 & 119.2 & - \\
\hline H-S-1.0 & 420 & 280 & 180 & 84 & 1302 & 7.4 & - & 77 \\
\hline
\end{tabular}

a Adjusted amount of mixing water considering the water content of nano-silica (aqueous solution with $50 \%$ solid content of $\mathrm{SiO}_{2}$ ).

** HRWRA: High Range Water Reducer Admixture.

\subsection{Tests}

Two tests were conducted to assess the effect of varying the dosages of BF pellets and incorporating SCMs on the fresh properties of the mixtures. The consistency of the mixtures was performed using the truncated cone and flow table method according to ASTM C230/C230M [28] and ASTM C1437 [29]. The mortar flow loss test, lasting up to $60 \mathrm{~min}$, was also conducted according to the latter standards.

To evaluate the hardened properties of the composites, the compressive strength, and flexural strength, pull-off tests were performed. To determine the compressive strength of the mixtures, triplicate cylinders $(100 \mathrm{~mm} \times 200 \mathrm{~mm})$ were tested at different ages according to ASTM C39 [30]. Since one of the main challenges with the layered structures is the interaction and bond between the materials, duplicate concrete slabs of $250 \mathrm{~mm} \times 250 \mathrm{~mm}$ surface area and $100 \mathrm{~mm}$ thickness were cast for each mixture following the same procedures mentioned earlier. After casting, the slabs were demolded and moist cured for 28 days in the curing room, then the slabs were partially cored to determine the pull-off strength according to ASTM C1583 [31].

To determine the flexural strength of the composites, triplicate standard prisms $(100 \mathrm{~mm} \times 100 \mathrm{~mm} \times 350 \mathrm{~mm})$ were tested according to ASTM C1609 [32]. A closed loop testing machine (Figure 2) was used to apply the load, where the deflection rate was controlled by the measured net mid-span deflection of the prism. The residual strength at net deflection of $(\ell / 600)$ and $(\ell / 150)$ was calculated based on Equation (1):

$$
f=p \ell /\left(b d^{2}\right)
$$


where, $f$ is the strength $(\mathrm{MPa}), P$ is the load $(\mathrm{N}), \ell$ is the span length $(\mathrm{mm}), b$ is the average width of the specimen at the fracture, as oriented for testing $(\mathrm{mm})$, and $\mathrm{d}$ is the average depth of the specimen at the fracture, as oriented for testing $(\mathrm{mm})$. In addition, the toughness herein was calculated following the ASTM C1609 [32] as the area under the load-deflection curve up to a displacement of $\ell / 150$ (i.e., $2 \mathrm{~mm}$ for the prism size used). In addition, the residual post-cracking strength index $\left(R_{i}\right)$ was calculated according to Equation (2):

$$
R_{i}=\left(\left(P_{0.5}+P_{0.75}+P_{1.0}+P_{1.25}\right) / 4\right) / P_{c r}
$$

where, $P_{0.5}, P_{0.75}, P_{1.0}$, and $P_{1.25}$ are the residual loads at deflections of $0.5,0.75,1.0$, and $1.25 \mathrm{~mm}$, and $P_{c r}$ is the peak load at first cracking.

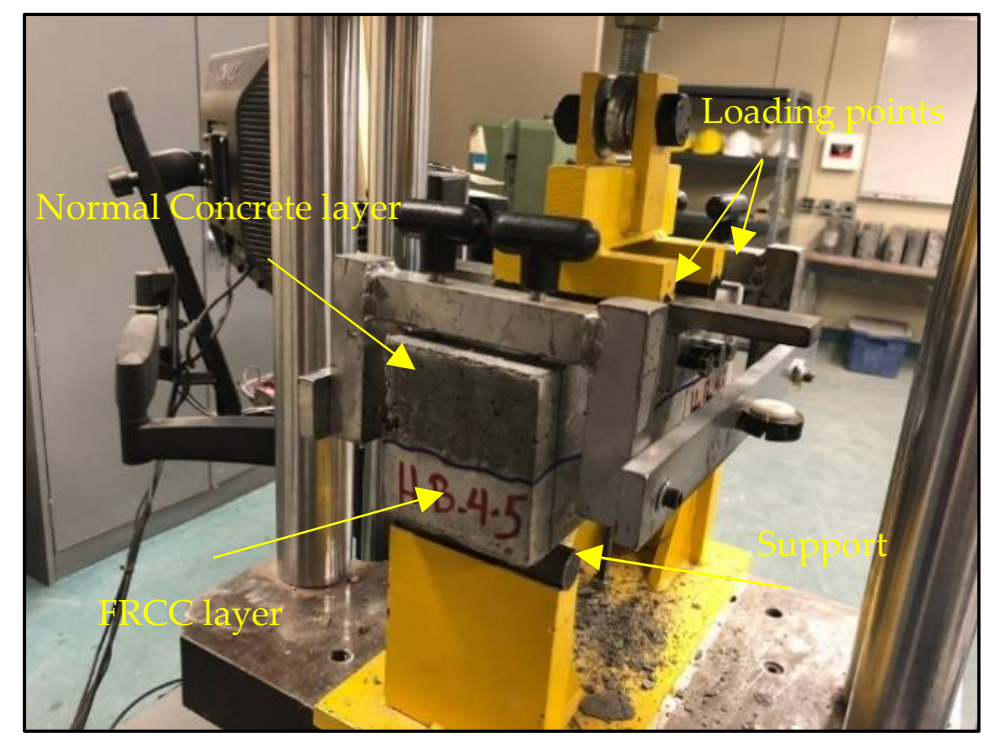

Figure 2. Flexural test set-up.

The interconnectivity of the pore system of the composites was assessed by the rapid chloride penetration test (RCPT) according to ASTM C1202 [33]. During the test period $(6 \mathrm{~h}), 60 \mathrm{~V}$ DC was applied to the cell compartments. The standard describes the data from RCPT in terms of passing charges through concrete that are continuously recorded to determine the penetrability class according to ASTM C1202. Since physical observations provide a better representation of the penetrability of chloride ions only into concrete, the physical penetration depth of chloride ions was measured in this study immediately after the completion of the test by spraying $0.1 \mathrm{M} \mathrm{AgNo}_{3}$ (silver nitrate) solution onto the surface of equally split discs. The discs were allowed to set under fluorescent light for approximately 15 min to obtain the whitish precipitate of silver chloride [34].

To complement the findings of the hardened properties, scanning electron microscopy (SEM) was employed on fracture pieces to assess the morphology of the BF pellets and to evaluate their characteristics in the cementitious matrix. The small pea-sized pieces were coated with carbon (thickness ranging from $50 \mathrm{~nm}$ to 500 Angstroms) to enhance the conductivity for the SCM.

\section{Test Results and Discussion \\ 3.1. Flowability}

The flowability is the resulting increase in average base diameter of the mortar mass, expressed as a percentage of the original base diameter, $D_{o}=100 \mathrm{~mm}$ in this study. The flow is the increase in average base diameter, expressed in $\mathrm{mm}$. The flow loss is the loss of workability with time, expressed in $\mathrm{mm}$. The flow, flowability, flow loss of the fresh cementitious composite mixtures with and without fibers are given in Table 4. The results illustrate the variation in the slump flow of composites reinforced with different dosages 
of BF pellets or SF. It is worth mentioning that the dosage of the superplasticizer was added at a constant dosage for the same type of the cementitious composite (see Table 3) to magnify the effect of adding fibers on the flowability of composites. All mixtures achieved a slump flow of $200 \pm 20 \mathrm{~mm}$ (flowability of $100 \pm 20 \%$ ), which is reaching the threshold of treating the composite as self-consolidating concrete of approximately $230 \mathrm{~mm}$ according to the CSA A23.1/CSA A23.2-19 [22], and the recommendation stipulated by Hunger [35]. The incorporation of SCMs such as slag and nano-silica required a greater dosage of superplasticizer to achieve the desired level of workability (see Table 3).

Table 4. Fresh properties of the cementitious composites.

\begin{tabular}{|c|c|c|c|c|c|c|c|}
\hline \multirow{3}{*}{ Mixture ID } & \multirow{3}{*}{${ }^{*} D(\mathrm{~mm})$} & \multirow{3}{*}{${ }^{* *}$ Flowability (\%) } & \multicolumn{5}{|c|}{ Flow Loss (mm) } \\
\hline & & & \multicolumn{5}{|c|}{ Test Time (min) } \\
\hline & & & 0 & 15 & 30 & 45 & 60 \\
\hline N-X-0.0 & 198 & 98 & 198 & 188 & 171 & 158 & 145 \\
\hline H-X-0.0 & 218 & 118 & 218 & 209 & 192 & 179 & 164 \\
\hline N-B-2.5 & 192 & 92 & 192 & 181 & 160 & 150 & 144 \\
\hline N-B-4.5 & 188 & 88 & 188 & 175 & 158 & 139 & 130 \\
\hline N-B-6.9 & 182 & 82 & 182 & 167 & 155 & 131 & 118 \\
\hline N-S-1.0 & 179 & 79 & 179 & 161 & 147 & 125 & 111 \\
\hline H-B-2.5 & 214 & 114 & 214 & 203 & 187 & 169 & 150 \\
\hline H-B-4.5 & 209 & 109 & 209 & 194 & 178 & 155 & 142 \\
\hline H-B-6.9 & 205 & 105 & 205 & 189 & 169 & 154 & 139 \\
\hline H-S-1.0 & 199 & 99 & 199 & 181 & 166 & 139 & 127 \\
\hline
\end{tabular}

*D: it is also referred as "Flow". ** $D_{0}$ was taken as $100 \mathrm{~mm}$ for all mixtures to calculate the flowability.

This can be attributed to the slag which had a highly angular shape and rough surface texture [36], in addition to the high specific surface area-to-volume ratio of the NS. Furthermore, it can be observed that the addition of BF pellets or SF had a negative effect on the workability, regardless the type of the cementitious composite. For example, adding $4.5 \%$ of BF pellets in both mixtures N-B-4.5 and H-B- 4.5 reduced the flowability by 10 and $7 \%$, respectively, compared to that of the counterpart specimens prepared without fibers. This can be attributed to the fact that the addition of fibers offered higher shear resistance to flow, which resulted in decreased flowability and stiffer fresh composites [37]. Moreover, increasing the dosage of the basalt fiber pellets was associated with a consistent reduction in the flowability of the cementitious composite. For instance, increasing the number of pellets from $2.5 \%$ in N-B-2.5 and H-B-2.5 to $6.9 \%$ in N-B-6.9 and H-B-6.9, respectively, led to an 11 and $8 \%$ reduction in the flow values. This might be due to increased surface area associated with the increase of fiber content. Compared to the control mixtures ( $\mathrm{N}-\mathrm{X}-0.0$ and $\mathrm{H}-\mathrm{X}-0.0$ ), the addition of $1.0 \%$ of steel fibers yielded a noticeable decrease in the flowability of 20 and $16 \%$, respectively. This can be attributed to the higher shear resistance to the flow of the composite offered by the metallic deformed fibers with relatively high modulus. These trends were similar to those reported by Yu et al. [38] and Wu et al. [39]. Moreover, irrespective of the type of the composite or the dosage of the pellets, all mixtures maintained reasonable flow up to $30 \mathrm{~min}$ after mixing, as the average flow loss was approximately $15 \%$ of the initial flow. After $60 \mathrm{~min}$, the mixtures maintained almost $69 \%$ of their initial values. These results emphasize the applicability of using such composites in the field in terms of moldability/placement and finishability operations since it possessed suitable flow properties.

\subsection{Compressive Strength}

The average compressive strength for the developed composites obtained from cylinders at different ages is listed in Table 5. 
Table 5. Compressive strength results for all mixtures.

\begin{tabular}{cccccc}
\hline & \multicolumn{5}{c}{ Compressive Strength (MPa) } \\
\cline { 2 - 6 } Mixture ID & \multicolumn{5}{c}{ Days } \\
\cline { 2 - 5 } & $\mathbf{3}$ & $\mathbf{7}$ & $\mathbf{2 8}$ & $\mathbf{5 6}$ & $\mathbf{9 0}$ \\
\cline { 2 - 5 } N-X-0.0 & 35.9 & 52.7 & 71.3 & 75.1 & 80.4 \\
H-X-0.0 & 67.8 & 81.5 & 94.5 & 96.1 & 99.2 \\
N-B-2.5 & 32.1 & 49.2 & 64.1 & 69.3 & 72.6 \\
N-B-4.5 & 30.4 & 46.3 & 59.1 & 63.4 & 70.5 \\
N-B-6.9 & 27.9 & 41.2 & 53.8 & 58.1 & 69.4 \\
N-S-1.0 & 39.8 & 50.2 & 78.7 & 83.2 & 85.1 \\
H-B-2.5 & 63.2 & 71.8 & 81.3 & 82.5 & 84.2 \\
H-B-4.5 & 59.8 & 64.4 & 70.3 & 72.4 & 75.2 \\
H-B-6.9 & 52.6 & 55.7 & 63.8 & 65.1 & 74.4 \\
H-S-1.0 & 69.4 & 84.6 & 98.8 & 101.3 & 102.2 \\
\hline
\end{tabular}

As evident by the compressive strength results, the addition of NS along with slag showed significantly more effect on the strength development, especially at early ages when it is compared to the corresponding reference mixture with cement only, regardless the type or dosage of the fibers. For example, the average compressive strength of the nano-modified slag-based composites was significantly increased by 97 and $48 \%$ at 3 and 7 days, respectively, compared to those of the reference cement-based specimens. The results were assessed by the analysis of variance (ANOVA) to determine whether there were any statistically significant differences between the means of compressive strength, as shown in Table 6. The t-test looked at the t-statistic, $\mathrm{t}$-distribution, and degrees of freedom to determine a $p$ value (probability) that could be used to determine whether the population means differ. The $\mathrm{t}$-test is one of several hypothesis tests. To compare three or more variables, statisticians use the analysis of variance (ANOVA). If the sample size is large, statisticians use a z-test. In addition, the authors have used ANOVA in their previous research rather than other statistical analyses that dealt with more than two variables. According to Montgomery [40], exceeding the $F_{c r}$ value of an F distribution density function indicates that the variable tested has a significant effect on the average results. The significant effect of incorporating SCMs was statistically supported by ANVOA for the compressive strength results at 3 and 7 days, since adding slag and NS yielded $F$ values of 64.0 and 15.2, which were greater than the $F_{c r}$ of 5.3. On the other hand, the latter strength development started to diminish at higher curing ages especially at 54 and 91 days, as the average compressive strengths of the $\mathrm{H}$ composites slightly increased by 20 and $14 \%$, respectively, with respect to the $\mathrm{N}$ composites. The reason behind the increasing values of compressive strength with time for the $\mathrm{N}$ composites was the progression of the hydration process, especially with the high volume of cement adopted in this study $\left(700 \mathrm{~kg} / \mathrm{m}^{3}\right)$. This was statistically supported by the ANOVA for the compressive strength results at 56 and 91 days, as the incorporation of SCMs yielded F values of 2.8 and 2.1, which were less than the $F_{c r}$ of 5.3, indicating that the effect of this parameter was statistically insignificant at later ages. 
Table 6. ANOVA for the results of compressive strength, flexural strength, and toughness at 28 days.

\begin{tabular}{|c|c|c|c|c|c|c|c|c|c|c|c|c|c|c|c|}
\hline \multirow{2}{*}{ Parameter } & \multicolumn{3}{|c|}{ Compressive Strength } & \multicolumn{3}{|c|}{ First-Peak Flexural Strength } & \multicolumn{3}{|c|}{ Toughness } & \multicolumn{3}{|c|}{ Penetration Depth } & \multicolumn{3}{|c|}{ Pull-Off } \\
\hline & $F$ & $F_{c r}$ & Effect & $F$ & $F_{c r}$ & Effect & $F$ & $F_{c r}$ & Effect & $F$ & $F_{c r}$ & Effect & $F$ & $F_{c r}$ & Effect \\
\hline \multicolumn{16}{|l|}{ Effect of the composite type } \\
\hline $\mathrm{N}$ vs. $\mathrm{H}$ composites at 3 days & 64.0 & 5.3 & $S$ & - & - & - & - & - & - & - & - & - & - & - & - \\
\hline $\mathrm{N}$ vs. $\mathrm{H}$ composites at 28 days & 6.1 & 5.3 & $S$ & 3.8 & 4.2 & I & 6.6 & 4.2 & $S$ & 19.2 & 5.3 & S & 0.35 & 4.1 & I \\
\hline $\mathrm{N}$ vs. $\mathrm{H}$ composites at 56 days & 2.8 & 5.3 & $\mathrm{I}$ & - & - & - & - & - & - & - & - & - & - & - & - \\
\hline $\mathrm{N}$ vs. $\mathrm{H}$ composites at 90 days & 2.1 & 5.3 & I & - & - & - & - & - & - & - & - & - & - & - & - \\
\hline \multicolumn{16}{|l|}{ Effect of the BF pellets } \\
\hline $\begin{array}{l}\text { H-B-2.5, H-B-4.5, H-B-6.9 vs. } \\
\text { N-X-0.0, H-X-0.0 }\end{array}$ & 6.0 & 4.1 & S & 0.4 & 4.2 & I & 52.4 & 4.3 & S & 2.1 & 4.1 & I & 164.0 & 4.2 & $\mathrm{~S}$ \\
\hline $\begin{array}{l}\text { Effect of the dosage of BF pellets } \\
\text { N-B-2.5, H-B-2.5 vs. N-B-6.9, } \\
\text { H-B-6.9 }\end{array}$ & 8.0 & 4.4 & $S$ & 10.2 & 5.0 & S & 6.1 & 5.0 & $\mathrm{~S}$ & 7.1 & 6.2 & $S$ & 1.38 & 4.6 & I \\
\hline $\begin{array}{l}\text { Effect of steel fibers } \\
\text { N-S-1.0, H-S-1.0 vs. N-X-0.0, } \\
\text { H-X-0.0 }\end{array}$ & 0.2 & 4.4 & I & 17.6 & 5.0 & I & 24.2 & 5.0 & S & 0.15 & 6.2 & I & 75.8 & 4.6 & $\mathrm{~S}$ \\
\hline \multicolumn{16}{|l|}{ Effect of fibers type } \\
\hline $\begin{array}{l}\text { H-B-2.5, H-B-4.5, H-B-6.9 vs. } \\
\text { H-S-1.0 }\end{array}$ & 3.6 & 4.4 & I & 3.5 & 5.0 & I & 0.4 & 5.0 & I & 0.36 & 6.2 & I & 0.74 & 4.6 & I \\
\hline \multicolumn{16}{|c|}{ Effect of BF pellets vs. steel fibers (constant stiffness) } \\
\hline $\begin{array}{l}\text { N-B-6.9, H-B-6.9 vs. N-S-1.0, } \\
\text { H-S-1.0 }\end{array}$ & 8.8 & 4.4 & S & 4.9 & 5.0 & I & 7.2 & 5.0 & S & 0.43 & 6.2 & I & 0.1 & 4.6 & I \\
\hline \multicolumn{16}{|c|}{ Effect of BF pellets vs. steel fibers (constant volume) } \\
\hline $\begin{array}{l}\text { N-B-2.5, H-B-2.5 vs. N-S-1.0, } \\
\text { H-S-1.0 }\end{array}$ & 2.2 & 4.4 & I & 3.9 & 5.0 & I & 0.06 & 5.0 & I & 0.21 & 6.2 & I & 0.4 & 4.6 & I \\
\hline \multicolumn{16}{|c|}{ Effect of BF pellets as a layer in the tension side } \\
\hline H-B-4.5 vs. F(H-B-4.5) & - & - & - & 1.2 & 7.7 & I & 3.2 & 7.7 & I & - & - & - & - & - & - \\
\hline
\end{tabular}


The effect of fiber inclusion on the compressive strength of concrete is controversial [41-43], as BFRCC at different dosages showed lower compressive strengths, compared to the control mixtures without fibers (N-X-0.0 and H-X-0.0). A similar trend was obtained by Branston et al. 2016 [43] for BF mini bars. The ANOVA showed that incorporating the $\mathrm{BF}$ pellets in the $\mathrm{N}$ and $\mathrm{H}$ matrices yielded an $\mathrm{F}$ value of 6.0 , which was higher than the critical value $\left(F_{c r}\right)$ of 4.1 , indicating that the effect of adding such fibers on the compressive strength was statistically significant. For example, the 28-day compressive strength was markedly reduced by 17 and $25 \%$ and 26 and $32.5 \%$, when the composite was reinforced with BF pellets at dosages of 4.5 and $6.9 \%$ for the $\mathrm{N}$ and $\mathrm{H}$ composites, respectively. This may be attributed to the formation of additional interfacial transitional zones (ITZs) in the matrix, and the reduced workability, which causes more air to be entrapped in the cementitious matrix after compacting, as previously observed by Mahmoud et al. [12]. In this context, varying the dosage of BF pellets from 2.5 to $6.9 \%$ led to a 16 and $22 \%$ decrease in the compressive strength value for the $\mathrm{N}$ and $\mathrm{H}$ composites, respectively. In addition, the ANOVA results revealed significant differences among the compressive strength results for the mixtures incorporating different dosages of BF pellets. For instance, increasing the dosage of BF pellets from 2.5 to $6.9 \%$ in both composites had an $F$ value of 8.0 compared to an $F_{c r}$ of 4.4 .

On the other hand, unlike the BF pellets, the incorporation of steel fibers showed a slight increase in the compressive strength quantitatively with respect to the two control mixtures. This was statistically supported by ANOVA for the compressive strength results, as adding SF yielded an $F$ value of 0.2 , which was less than the $F_{c r}$ of 4.4 . This insignificant effect might be ascribed to the small volumes of SF introduced to the cementitious matrix, as the dosage of the SF corresponded to the lowest dosage in the BF. Nevertheless, the failure mode was considerably altered from brittle to ductile, as the bridging effect of the fibers maintained the integrity of the cylinders up to the end of the test, as depicted in Figure 3. It is worth noting that the compressive strength was marginally affected by the properties of fibers (modulus of elasticity and aspect ratio). The incorporation of fibers, regardless of the fiber type, usually contributes to increasing air bubbles in the matrix, and thus, reducing its strength [44,45]. This was confirmed by ANOVA for the compressive strength results, as replacing the BF pellets with steel fibers in the $\mathrm{N}$ and $\mathrm{H}$ composites yielded $F$ values of 2.5 and 3.6, which were smaller than the $F_{c r}$ value of 4.4 (Table 6).

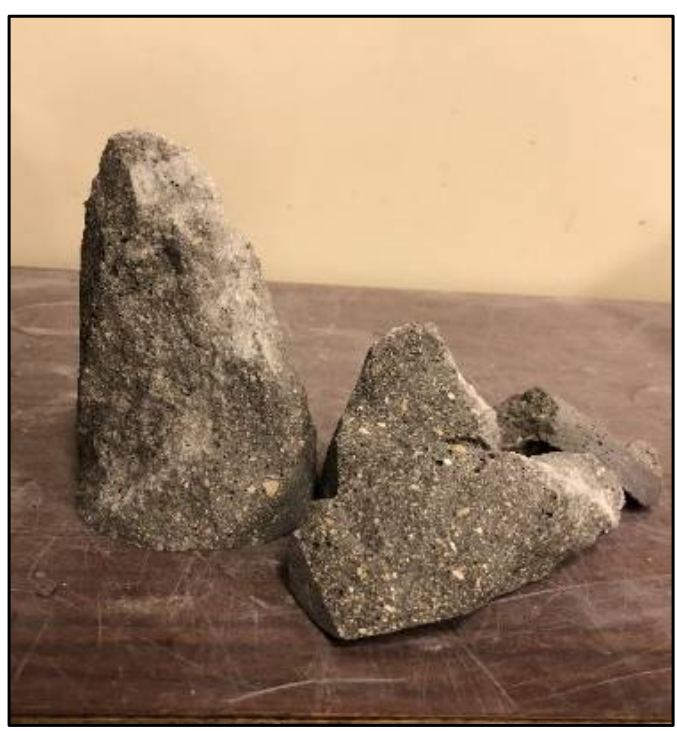

(a)

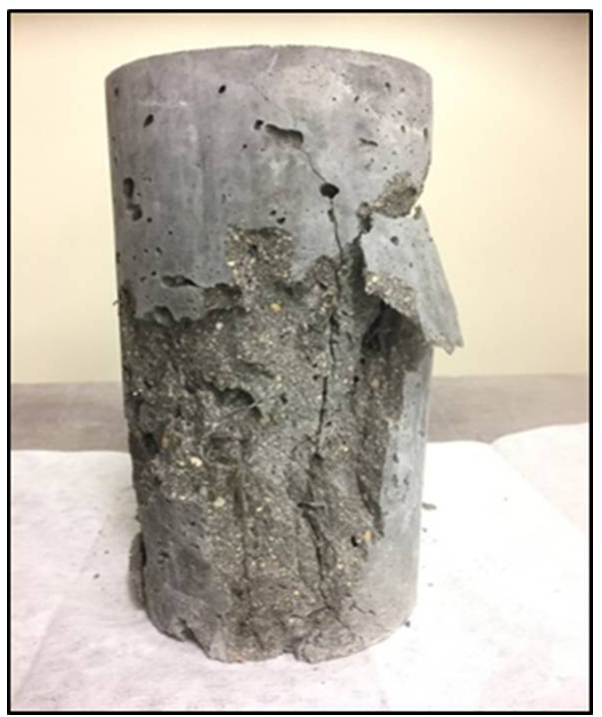

(b)

Figure 3. Mode of failure of specimens: (a) without fibers, and (b) with steel fibers. 
This trend is highlighting the predominant role of the cementitious matrix in significantly reducing/increasing the compressive strength, rather than the type of fiber (BF pellets or SF). In addition, when the volume was kept constant, the same observation was found; replacing $2.5 \%$ of BF pellets with 1.0\% SF yielded an F value of 2.2, which is less than the $F_{c r}$ value of 4.4 .

\subsection{Flexural Strength and Toughness}

The flexural and residual strength, as well as toughness and residual post-cracking strength index $\left(R_{i}\right)$, for all mixtures at 28 days are listed in Table 7 . In general, complying with the compressive strength results, the $\mathrm{H}$ composites were supposed to have an improved pre-cracking performance in terms of the first-peak strength, despite the fibers type or dosage included, in comparison to that of the counterpart specimens without slag and nano-silica (N composites). However, unexpectedly, the incorporation of SCMs did not significantly affect the first-peak strength, as the trends of both the $\mathrm{N}$ and $\mathrm{H}$ composites were quite comparable (see Table 7). This was due to the $\mathrm{N}$ composites being made with a high-volume cement $\left(700 \mathrm{~kg} / \mathrm{m}^{3}\right)$ in addition to the continual curing up to 28 days, which resulted in significant increase in its strength. These strengths, which exceeded the limit that defines the high strength concrete with $55 \mathrm{MPa}$ [46], were similar to the strength of the $\mathrm{H}$ composites at 28 days (see Table 5 ). This was statistically supported by the ANOVA for the first-peak strength at 28 days, as changing the cementitious composites from $\mathrm{N}$ to $\mathrm{H}$ yielded $F$ value of 3.8, which was less than the $F_{c r}$ of 4.2 , indicating that the effect of this parameter on the pre-peak stage was statistically insignificant.

Table 7. Mechanical properties of the cementitious composites.

\begin{tabular}{|c|c|c|c|c|c|}
\hline \multirow[b]{2}{*}{ Mixture ID } & \multicolumn{5}{|c|}{ Flexural Test Results at 28 days } \\
\hline & $\begin{array}{c}\text { First-Peak } \\
\text { Strength (MPa) }\end{array}$ & $\begin{array}{l}\text { Residual Strength } \\
\text { l/600 (MPa) }\end{array}$ & $\begin{array}{c}\text { Residual Strength } \\
\ell / 150(\mathrm{MPa})\end{array}$ & $\begin{array}{l}\text { Residual Post-Cracking } \\
\text { Strength Index }\left(R_{i}\right)\end{array}$ & Toughness $(J)$ \\
\hline N-X-0.0 & 5.8 & 0.6 & 0.5 & 0.1 & 8.2 \\
\hline H-X-0.0 & 7.1 & 1.2 & 1.8 & 0.2 & 13.1 \\
\hline N-B-2.5 & 6.8 & 3.6 & 4.0 & 0.6 & 26.8 \\
\hline N-B-4.5 & 5.8 & 4.9 & 4.6 & 0.9 & 32.0 \\
\hline N-B-6.9 & 5.6 & 5.4 & 4.5 & 0.9 & 33.4 \\
\hline N-S-1.0 & 7.1 & 4.6 & 1.8 & 0.4 & 23.5 \\
\hline H-B-2.5 & 6.8 & 5.2 & 5.0 & 0.8 & 33.8 \\
\hline H-B-4.5 & 6.6 & 7.8 & 7.6 & 1.1 & 47.4 \\
\hline H-B-6.9 & 6.1 & 7.8 & 7.4 & 1.2 & 45.2 \\
\hline H-S-1.0 & 7.4 & 7.3 & 4.6 & 0.8 & 39.4 \\
\hline
\end{tabular}

Consistently, the fibers had marginal effect on the behavior during the pre-cracking stage, which was mainly dependent on the properties of the cementitious matrix. The first-crack strength (first-peak strength) for all fiber-reinforced composites ( $\mathrm{N}$ and $\mathrm{H}$ composites) with either BF or SFs, showed comparable values with respect to the control mixture without fibers. This trend was statistically substantiated by the ANOVA results, as incorporating the BF pellets in the $\mathrm{N}$ and $\mathrm{H}$ matrices yielded an $F$ value of 0.4 , which was less than the critical value $\left(F_{c r}\right)$ of 4.2 , indicating that the effect of adding such fibers on the first-crack strength was statistically insignificant. Similarly, replacing the BF pellets with SF did not show any distinctive difference in terms of the first-crack strength, even if the modular ratio and the volume were kept constant; such insignificant effect was also validated by the ANOVA results (see Table 6). This behavior may be explained as follows. At the pre-cracking stage, although both the fiber and the cementitious matrix sustained loads together, the relatively low stress resulted in similar bond stress for the BFRCC and SFRCC with different fiber contents; however, after cracking, only fibers sustained loads through different mechanisms. 
The P- $\delta$ (load-deflection) curves for all test prisms are shown in Figure 4 . The reported mid-span deflection represents the average readings from two LVDTs that were in contact with a bracket attached to each specimen. As expected, the prism made without any fibers did not show any significant residual strength after cracking and broke in a brittle manner, and the sudden drop in the load after reaching the peak was observed due to the presence of synthetic fibers in the top layer. Whereas all FRCC prisms, irrespective of the type or dosages of fibers added to the mixture, exhibited improved post-cracking behavior due to deformation and pull-out mechanisms of the BF pellets and the SF.
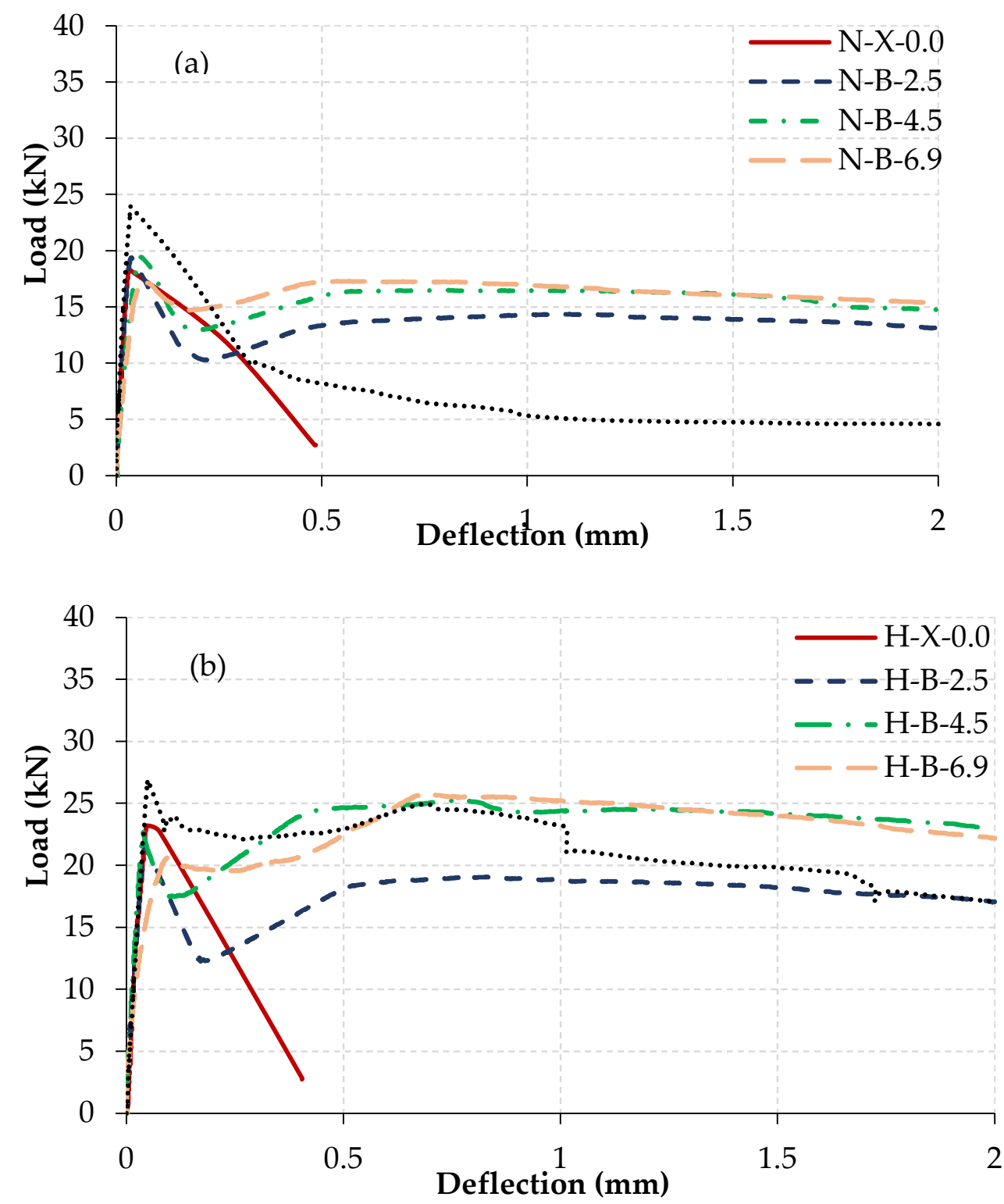

Figure 4. Load-deflection (P- $\delta$ ) curves for layered specimens: (a) N composites, and (b) H composites.

After the first cracking, the prisms did not fail but continued to carry either decreasing loads (N-B-2.5, N-B-4.5, N-B-6.9, N-S-1.0, H-B-2.5, and H-S-1.0) or increasing loads (H-B-4.5 or H-B-6.9). The post-cracking behavior of the former prisms was associated with a sudden drop (an average drop of $30 \%$ at approximately $0.2 \mathrm{~mm}$ deflection) in the load. However, the fibers in these prisms were able to control the crack exhibiting a notable increase in composite fracture resistance, which was accompanied by a slight increase in load carrying capacity but not exceeding the initial cracking load. As for the later prisms, no drop in the load was observed, but it continued to carry increasing loads, whereas the peak 
load of the composite was notably greater than that of the load at the first cracking. The prisms reinforced with high dosages of BF pellets (H-B-4.5 and H-B-6.9) exhibited a pseudo strain hardening behavior, similar to Engineered Cementitious Composites, which nearly behave as ductile metals [47]. The prisms from H-B-4.5 and H-B-6.9 achieved the highest post-cracking behavior, as the residual strengths at a deflection of $0.5 \mathrm{~mm}(\mathrm{span} / 600)$ were approximately 18 and $27 \%$ higher than the first crack strength of both mixtures, respectively. At a deflection of $2 \mathrm{~mm}$ (span/150), these percentages were approximately 15 and $21 \%$ for both mixtures, respectively. Such distinctive behavior beyond the first cracking for both mixtures (B-4.5 and B-6.9) substantiates the well-documented notion that effective types of fibers are mainly incorporated to significantly enhance the flexural behaviour [4]. This trend might be attributed to the adequate distribution of BF pellets over the cross-section of the layer and the intensity of fibers, which improved their effectiveness in controlling crack propagation in the matrix by redistributing micro-cracks (Figure 5). In addition, the improved bonding with the cementitious matrix resulted in the gradual pull-out failure rather than the rupture of the pellets, as was substantiated by the SEM.

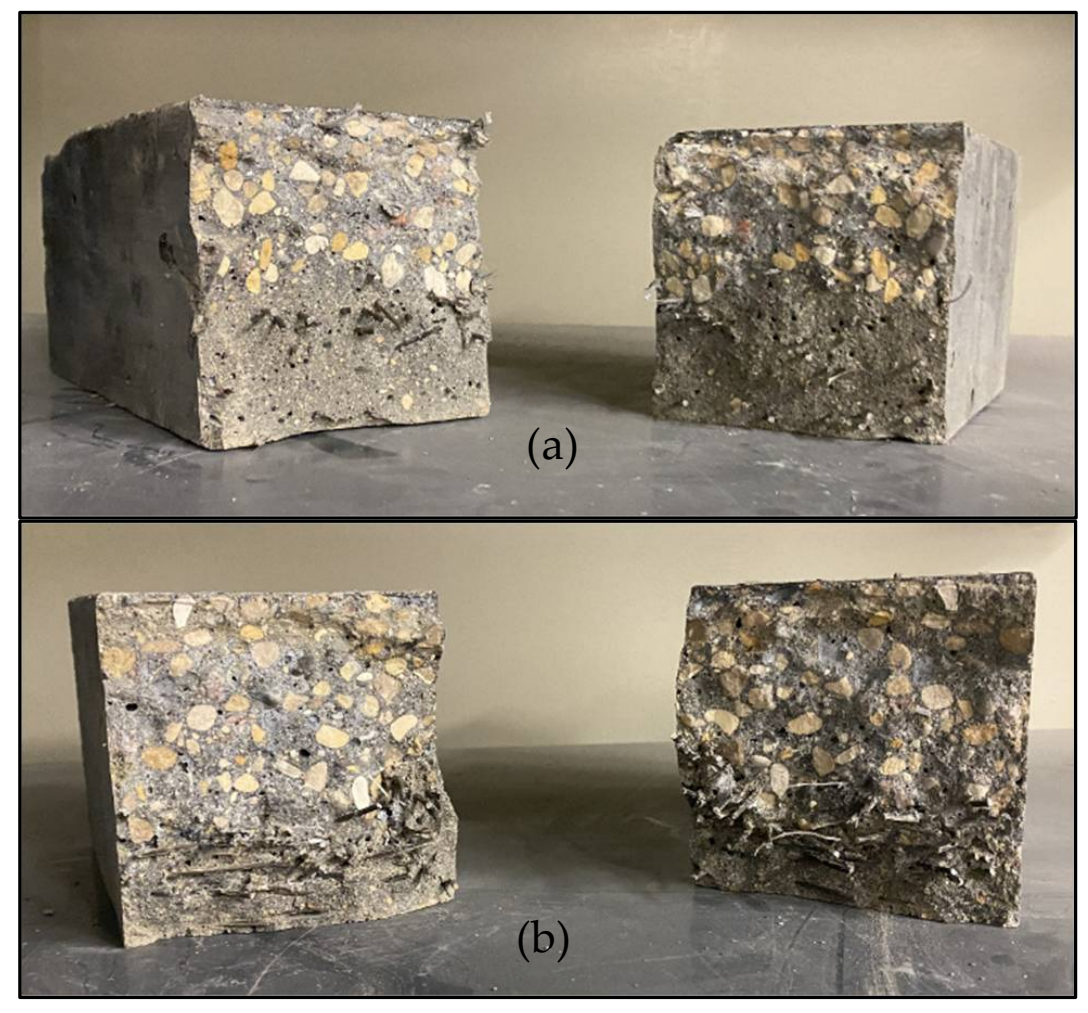

Figure 5. Distribution of BF pellets at the failure planes of: (a) H-B-2.5, and (b) H-B-6.9.

The P- $\delta$ curves are usually used qualitatively to examine the overall performance of the various FRCC. However, to quantitatively evaluate the behaviour of FRCC, two techniques were adopted: the toughness and the residual index. First, despite the minimal effect of the SCMs on the pre-cracking stage, the incorporation of slag and nano-silica contributed to improving the post-cracking behaviour with statistical significance (Table 6). For example, replacing $40 \%$ cement content with slag and adding $6 \%$ NS increased the average toughness and residual index for all mixtures by 45 and $42 \%$, respectively, irrespective of the type or dosage of fiber. This behavior may be attributable to the higher degree of hydration and improved quality of the ITZ between the fibers and cement paste due to the process by which the load is transferred from the cementitious matrix to the fibers to bridge the cracks.

In the same context, the Ri results of the $\mathrm{N}$ and $\mathrm{H}$ composites containing $\mathrm{BF}$ pellets or SF have remained above the level (0-0.3) specified by the Canadian Highway Bridge Design Code, CHBDC [48] based on the application and the number of directions of 
conventional cracking control reinforcement, to be adequate for an efficient post-cracking performance. For instance, the incorporation of $4.5 \% \mathrm{BF}$ pellets in the $\mathrm{N}$ and $\mathrm{H}$ composites yielded $R_{i}$ values of 0.94 and 1.1, respectively, compared to that of the counterpart mixtures prepared without fibers, which were 0.1 and 0.2 , respectively. Albeit the BF pellets had lower modulus of elasticity and aspect ratio with respect to the $\mathrm{SF}$, a superior post-cracking behavior was observed for both cementitious composites in terms of residual strength at both deflections $(\ell / 600$ and $\ell / 150)$, residual index, and fracture energy (toughness). To keep the ratio of volume of $\mathrm{BF}$ pellets to $\mathrm{SF}$ equal to the modular ratio, the toughness was markedly increased. For instance, replacing $1.0 \%$ of SF with $6.9 \%$ BF pellets in both cementitious composites (N-B-6.9 and H-B-6.9) led to a significant increase of 42 and 15\%, respectively, in the toughness, which was also confirmed by the ANOVA results (see Table 6). Interestingly, when the volume of both fibers was kept constant, taking into consideration the superior properties of SF with respect to the BF pellets, the post-cracking behavior was quite comparable, as shown in Figure 4. Accordingly, replacing 2.5\% BF pellets with $1.0 \%$ SF had an insignificant effect on the toughness results. This trend was also substantiated by the ANOVA results, as incorporating the same volume of both types into the matrix yielded an $F$ value of 0.06 , which was much lower than the critical value $\left(F_{c r}\right)$ of 5.0. This may be ascribed to the enhanced bonding of the cementitious composite within the textured grooves in the longitudinal direction of the BF pellets, which provided a host for the deposition of the hydration products, as shown in Figure 6.

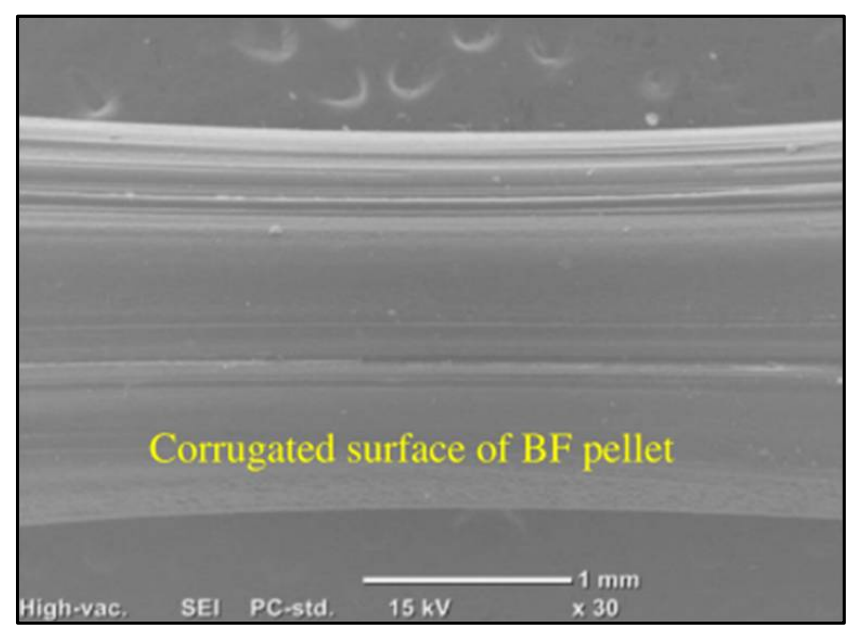

(a)

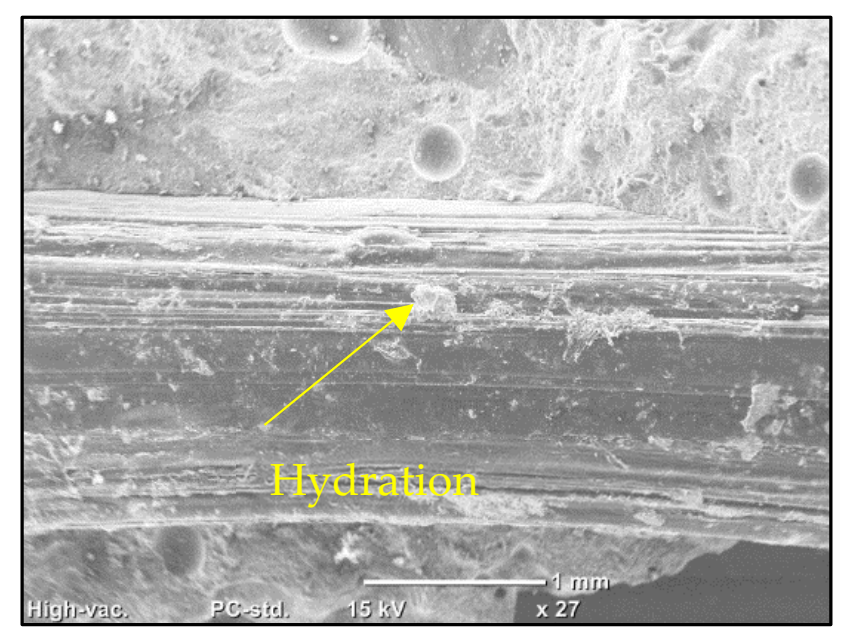

(b)

Figure 6. SEM images for (a) the morphology of the BF pellet surface; (b) hydration products in BF pellet grooves.

To assess the effectiveness of incorporating the FRCC as a layer, not over the whole cross-section, on improving the post-cracking behaviour, additional sets of prisms were cast and tested following the guidelines of ASTM C1609 [32].

The whole cross-section of the specimens was cast using the $\mathrm{H}$ cementitious composites and was reinforced with BF pellets at different dosages of $2.5,4.5$, and $6.9 \%$. To differentiate the nomenclature of the full depth specimens from the layered specimens, a letter F preceded the full depth specimen's name. Table 8 lists the flexural strength parameters for the full depth specimens at 28 days, based on the load-deflection curve shown in Figure 7. At a fixed fiber dosage, the toughness of the layered specimens was slightly lower than that of their full depth counterparts. The ANOVA results revealed insignificant differences among the toughness calculations for the layered and full depth prisms. For example, incorporating $4.5 \%$ BF pellets over the whole depth of the prism had an $F$ value of 3.2 compared to an $F_{c r}$ of 7.7 (Table 6). This may be ascribed to the well-documented trend that the contribution of fibers to enhance compressive strength is 
negligible, and these findings support the authors' notion that it is more economical and effective in practice to incorporate the FRCC as a layer in the tension side only.

Table 8. Mechanical properties of the full depth specimens at 28 days.

\begin{tabular}{cccccc}
\hline & \multicolumn{5}{c}{ Flexural Test Results at 28 Days } \\
\cline { 2 - 6 } Mixture ID & $\begin{array}{c}\text { First-Peak } \\
\text { Strength (MPa) }\end{array}$ & $\begin{array}{c}\text { Residual Strength } \\
\ell / \mathbf{6 0 0} \mathbf{( M P a )}\end{array}$ & $\begin{array}{c}\text { Residual Strength } \\
\ell / \mathbf{1 5 0} \mathbf{( M P a})\end{array}$ & $\begin{array}{c}\text { Residual Post-Cracking } \\
\text { Strength Index }\left(\boldsymbol{R}_{\boldsymbol{i}}\right)\end{array}$ & Toughness $(\boldsymbol{J})$ \\
\hline F(H-X-0.0) & 8.6 & - & - & - & $0.9^{\mathrm{a}}$ \\
F(H-B-2.5) & 7.6 & 4.9 & 4.1 & 0.68 & 32.1 \\
F(H-B-4.5) & 6.4 & 8.6 & 7.7 & 1.42 & 54.9 \\
F(H-B-6.9) & 5.8 & 8.8 & 7.9 & 1.72 & 56.5 \\
\hline
\end{tabular}

${ }^{a}$ Toughness calculated as the area under the P- $\delta$ curve from 0 to the peak load deflection.

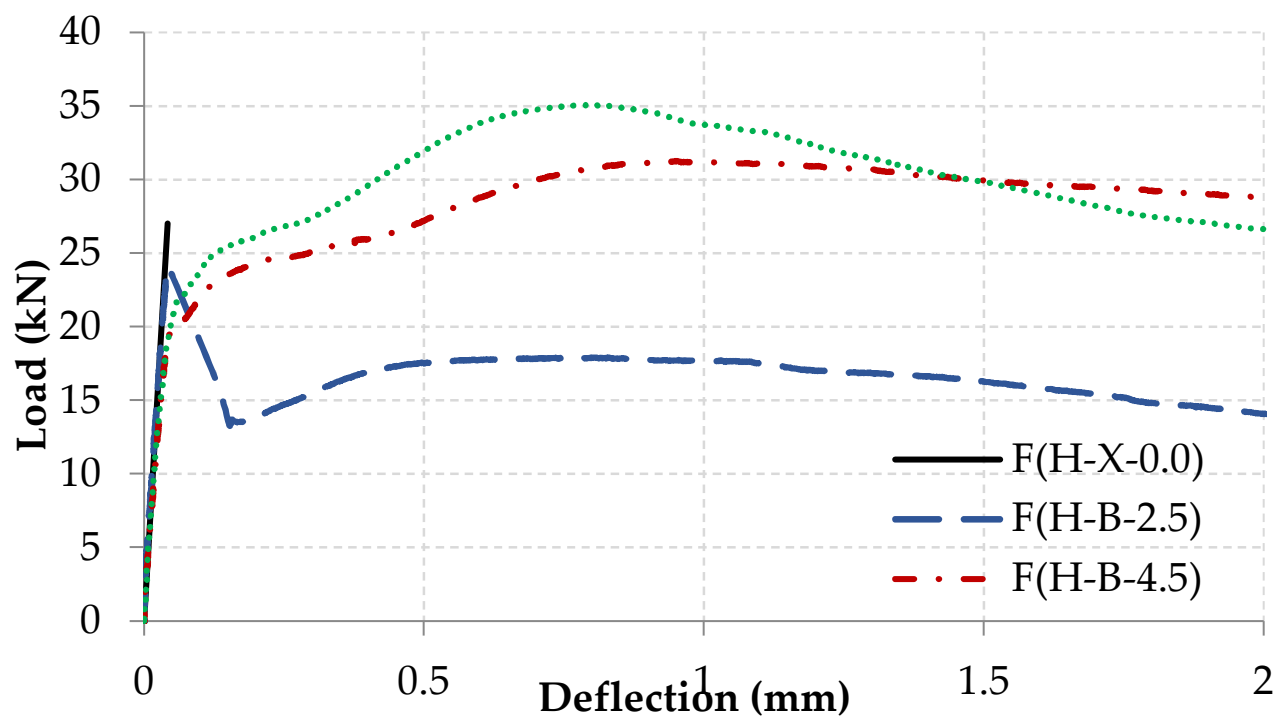

Figure 7. Load-deflection (P- $\delta$ ) curves for full depth specimens.

\subsection{Bond Strength}

There has been an increasing demand to optimize the structural element, and this can be achieved by combining two different materials. Such composite structures are often named as a layered or hybrid structure, where the interaction and bond between the different materials are considered as a major challenge for design engineers, as bond failure is a critical cause of deterioration in layered structures. Therefore, the pull-off test was adopted to evaluate the monolithic behaviour between the FRCC layer with base the concrete and capture the risk results from the incompatibility between the two layers. It is worth mentioning that the specimens in the pull-off test are subjected to pure tensile stresses, which represents a severe scenario for the specimen.

The average bond strength values obtained from eight cores for each mixture at 28 days are shown in Figure 8. The results showed that the mixtures prepared without any fibers (N-X-0.0 and $\mathrm{H}-\mathrm{X}-0.0)$ had a bond strength of 1.44 and $2.2 \mathrm{MPa}$, respectively. Both mixtures experienced an undesirable mode of failure, as the failure occurred mainly in the composite itself, as shown in Figure 9. This may be ascribed to the $\mathrm{N}$ and $\mathrm{H}$ composites, prepared without any fibers, which had tensile strength lower than that of the base concrete, the bond line between the two layers or the epoxy used to bond the steel disk. Compared to the control mixture N-X-0.0, there was a slight improvement in the bond strength of the H-X-0.0 mixture; this can be ascribed to the synergistic effects of nano-silica and slag, resulting in the densification of the microstructure. On the other hand, according to the CHBDC [48], it is stipulated that the concrete base should have a minimum bond strength of 1.5 MPa for bond-critical applications. The results herein indicated that the inclusion 
of fibers in the $\mathrm{N}$ and $\mathrm{H}$ composites, despite the type or the dosage, markedly improved the bond strength, which were in the range from 3.51-3.89 MPa. For example, adding BF pellets at dosages of $2.5,4.5 \%$, and $6.9 \%$ in the $\mathrm{H}$ composite enhanced the bond strength by 73,70 , and $68 \%$, respectively. This significant effect of incorporating discrete fibers was statistically supported by ANOVA for the bond strength, since adding BF pellets to the $\mathrm{H}$ composites at different dosages yielded an $F$ value of 164.0, which was greater than the $F_{c r}$ of 4.2. At a fixed BF pellet dosage, changing the cementitious composite from $\mathrm{N}$ to $\mathrm{H}$ showed a negligible improvement in the bond strength, with statistical insignificance (Table 5). Consistently, increasing the BF dosage or using steel fibers instead did not contribute to enhancing the bond strength. Therefore, the bond strength for all fibrous composites were quite similar, and this may be attributed to the failure of all specimens containing BF pellets or SF shifting toward the base concrete (see Figure 9), suggesting that the assembly behaved as an integral system with a high degree of compatibility.

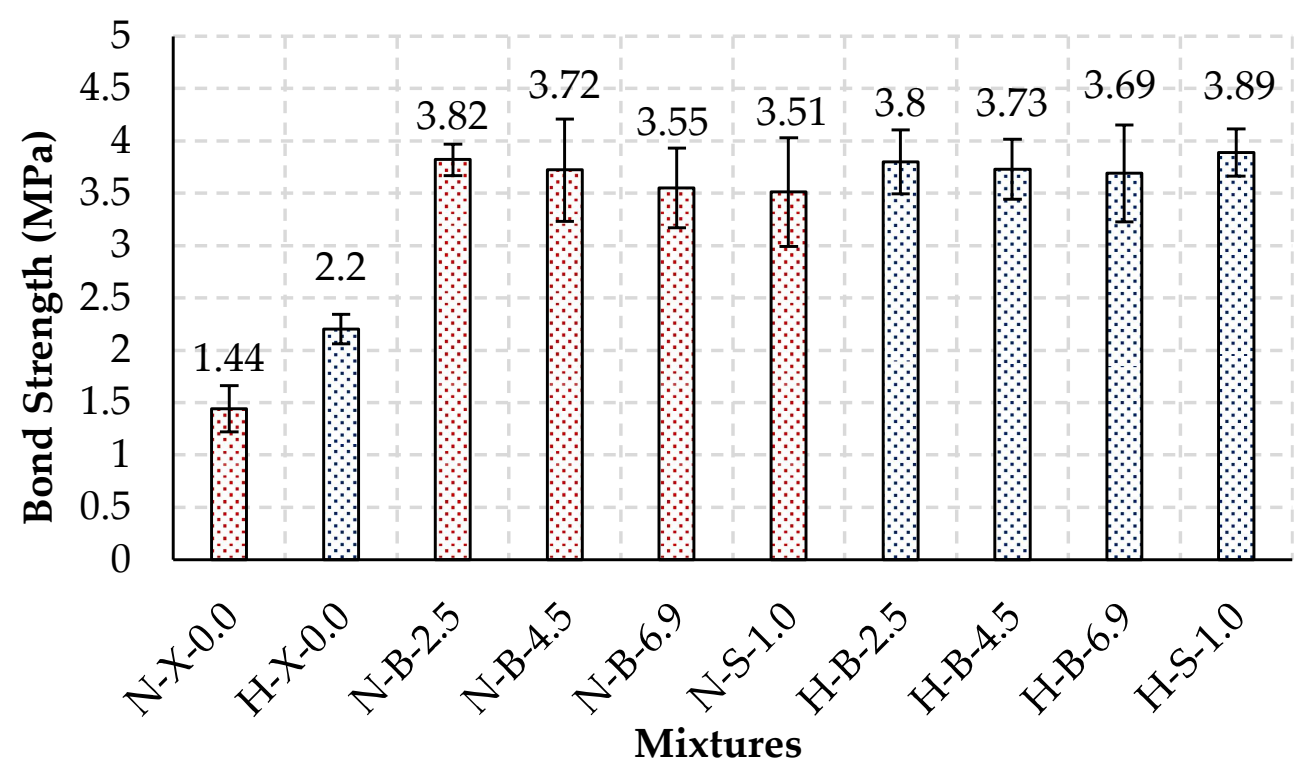

Figure 8. Bond strength of all mixtures from pull-off test.
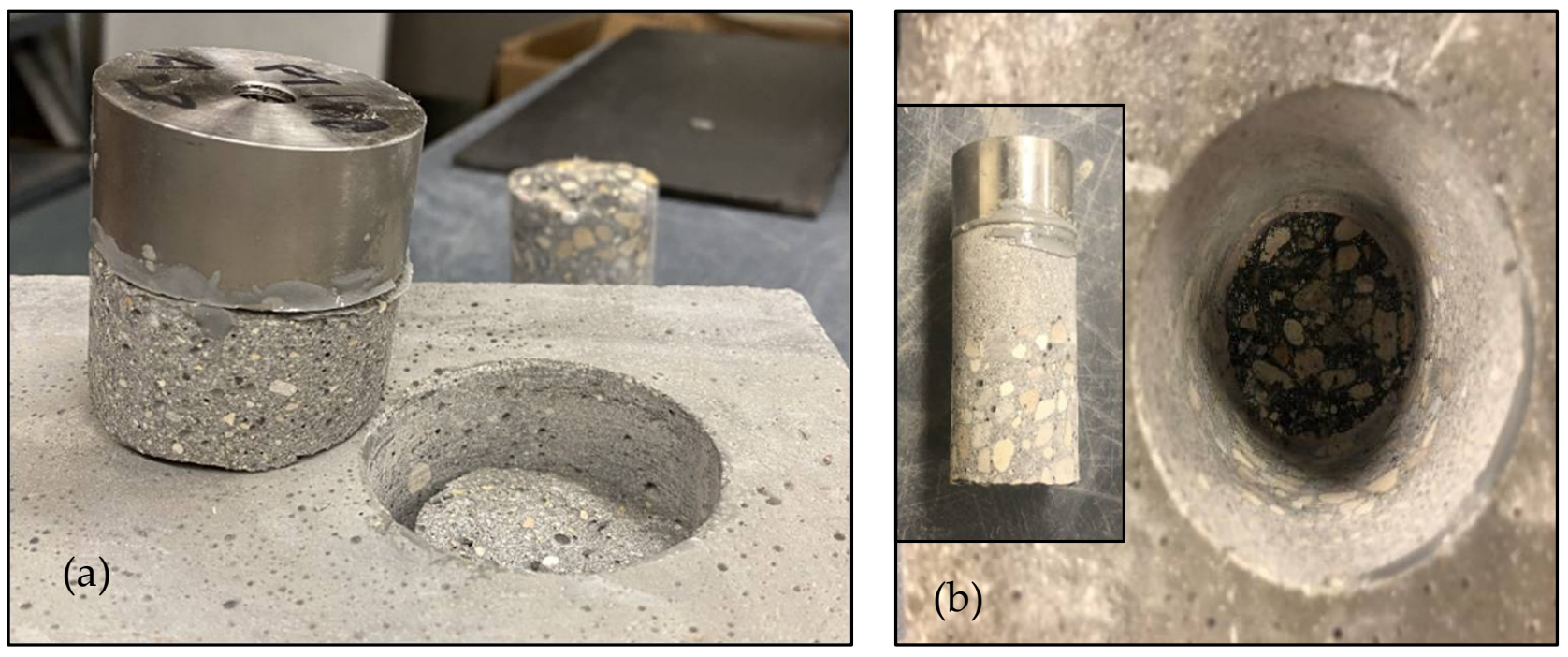

Figure 9. Exemplar mode of failure from the pull-off test for (a) H-X-0.0; (b) H-B-2.5. 


\subsection{Penetrability}

Penetrability is considered a major factor that affects the durability/longevity of cementitious composites in their resistance to the ingress of moisture and aggressive substances and was assessed by the RCPT test at 28 days. The average penetration depth, the results of passing charges, and the corresponding penetrability class according to ASTM C1202 [33] are listed in Table 9. According to the qualitative indication of the chloride ion penetrability, the cement-based composites, irrespective to the type and dosage of the fibers included, had low penetrability since the passing charges fall in the range from 1000-2000 coulombs. On the other hand, the inclusion of SCMs such as slag and nanosilica, despite the type or the dosage of fibers, significantly reduced the passing charges to become lower than 1,000 coulombs, which can be classified as "very low" penetrability as per ASTM C1202 [33]. For example, the passing charges of H-X-0.0, H-B-2.5, H-B-4.5, H-B-6.9, and H-S-1.0 specimens were 64, 70, 69, 66, and 60\% less than that of N-X-0.0, N-B-2.5, N-B-4.5, N-B-6.9, and N-S-1.0 specimens. This trend was substantiated by the physical penetration depth results, as these mixtures had markedly lower penetration depths (less than $8 \mathrm{~mm}$ ) relative to that of the counterpart mixtures cast with cement only. Exemplar measurements for the penetration depth are shown in Figure 10. This was ascribed to the smaller particle size of nano-silica (approximately $35 \mathrm{~nm}$ ), which provides a huge surface area $\left(80,000 \mathrm{~m}^{2} / \mathrm{kg}\right)$, as it vigorously speeds up the rate of cement hydration. In addition, nano-silica can contribute physical filler and pozzolanic effects to the cementitious matrix, which led to densifying the cementitious matrix and increasing its chloride penetration resistance.

Table 9. Average RCPT results.

\begin{tabular}{cccc}
\hline Mixture ID & Passing Charge (C) & $\begin{array}{c}\text { Physical Chloride } \\
\text { Penetration Depth (mm) }\end{array}$ & $\begin{array}{c}\text { Chloride Ion Penetrability } \\
\text { Class (ASTM C1202) }\end{array}$ \\
\hline N-X-0.0 & 1,103 & 11.3 & Low \\
H-X-0.0 & 398 & 3.1 & Very Low \\
N-B-2.5 & 1,506 & 12.7 & Low \\
N-B-4.5 & 1,674 & 13.9 & Low \\
N-B-6.9 & 1,798 & 15.2 & Low \\
N-S-1.0 & 1,843 & 11.9 & Low \\
H-B-2.5 & 463 & 4.5 & Very Low \\
H-B-4.5 & 516 & 5.7 & Very Low \\
H-B-6.9 & 617 & 7.9 & Very Low \\
H-S-1.0 & 732 & 4.2 & Very Low \\
\hline
\end{tabular}

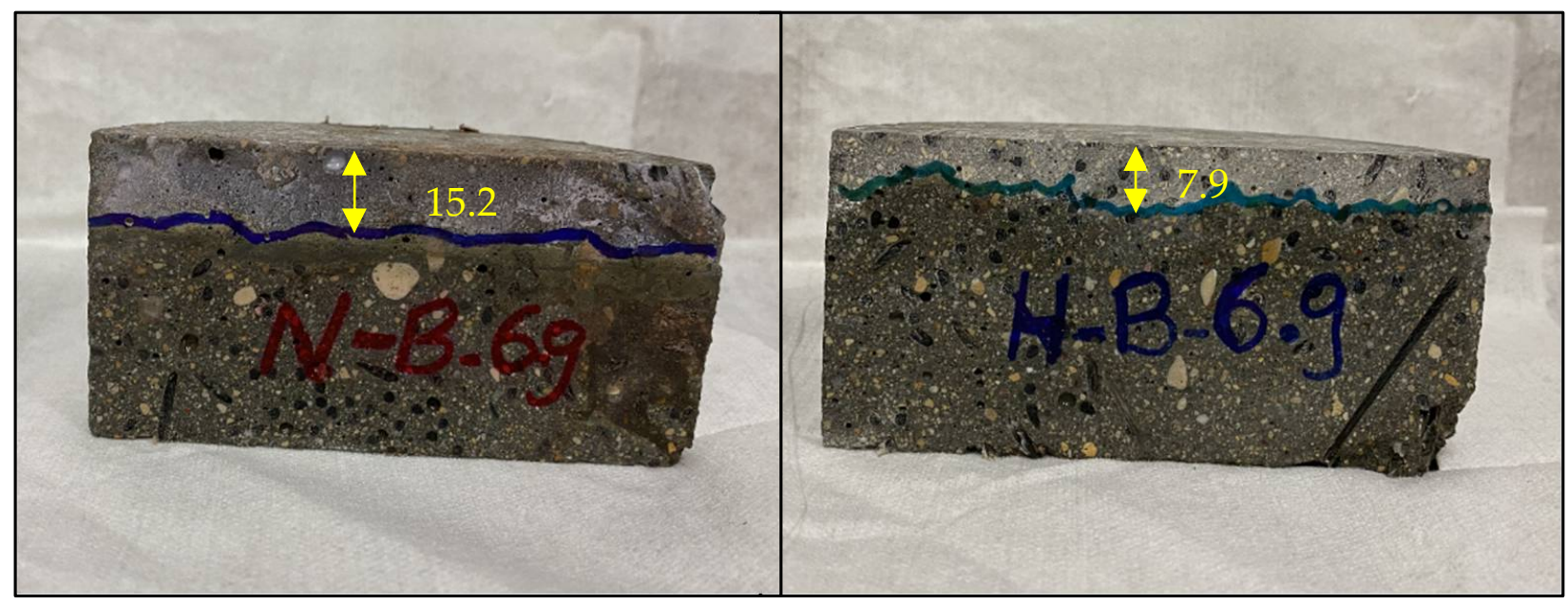

Figure 10. Whitish precipitate indicating the penetration depth of chloride ions into the N-B- 6.9 and H-B-6.9 composites. 
Although adding discrete fibers had several advantages, it was also reported that fibers introduce more transition zones in the matrix resulting in increased permeability [14,49]. Conforming to the strength results, the chloride penetration resistance decreased with the addition of BF pellets compared to the control mix, which contains zero fiber, despite the cementitious composite type. For example, the control mixtures N-X-0.0 and H-X-0.0 had passing charges and penetration depths of 1,103 and 398 coulombs, and 11.3 and $3.1 \mathrm{~mm}$, respectively. These values were significantly increased to 1,798 and 617 coulombs, and 15.2 and $7.9 \mathrm{~mm}$, respectively (Table 9) when BF Pellets were incorporated at a higher dosage of $6.9 \%$ in both mixtures (N-B-6.9 and H-B-6.9). In the same context, increasing the $\mathrm{BF}$ dosages led to the increased penetrability of the composites. Increasing the dosage of BF pellets from 2.5 to 4.5 and further to $6.9 \%$ in the $\mathrm{N}$ composites led to a 12 and $20 \%$ increase in the passing charges. Correspondingly, for the $\mathrm{H}$ composites, these values were 11 and $33 \%$ higher for the 4.5 and $6.9 \%$ BF pellet specimens than that of the $2.5 \%$ specimens.

From Table 9, it can be noted that the specimens containing SF, irrespective of the cementitious composite type, had higher passing charges than those of corresponding specimens comprising BF pellets. This was attributed to the RCPT test based on electrical conductivity as the presence of steel or metallic fibers enhanced the conductivity of the specimens, depending on their continuity in the matrix, and produced misleading results in terms of the charges migrating through the specimen. A similar observation was reported by Hossain et al. [50] and Ghazy et al. [49]. As such, this highlighted the role of using an alternative measurement (chloride penetration depth), which better correlates to the physical characteristics of the pore structure of the cementitious matrix to alleviate and capture biases induced by conductive material (e.g., steel fibers) that influence the resistivity of the cementitious matrix. For example, including SF in the $\mathrm{N}$ and $\mathrm{H}$ composites yielded the highest passing charges with 1,843 and 732 coulombs, respectively, which would give the impression that the specimens containing SF had a pore structure that would facilitate the ingress of fluids into the matrix. However, interestingly, the penetration depths for both mixtures, N-S-1.0 and H-S-1.0, were 11.9 and $4.2 \mathrm{~mm}$, respectively, which were less than the penetration depths for all specimens containing BF pellets, despite the dosage included.

\section{Conclusions}

Based on the specific material types, mixture designs, and tests implemented in this study, the following conclusions can be drawn:

- The inclusion of SF in the H composites reduced the flowability, whereas the replacement of SFs by BF pellets at different dosages had less effect on the flowability and flow loss, which makes the BFRCC suitable for field applications in terms of the placement and finishability process.

- The results generally show that the early-age and later-age compressive strength of the $\mathrm{H}$ composites comprising different types and dosages of fibers markedly improved, as all values were above $55 \mathrm{MPa}$ at seven days. Hence, the inherently slower rate of strength development of cementitious systems containing slag can be controlled by the addition of a small dosage ( $6 \%$ ) of nano-silica.

- Compared to the control mixtures without fibers, BFRCC mixtures with fibers yielded lower compressive strength, especially with higher dosages of BF pellets; however, the mode of failure considerably changed from brittle to ductile.

- The layered prisms reinforced with high dosages of BF pellets (H-B-4.5 and H-B-6.9) exhibited a pseudo strain-hardening process (ranging between 47 and $45 \mathrm{~J}$ ), while the prisms reinforced with SF (H-S-1.0) showed a strain-softening behavior.

- Keeping the volume of BF pellets and SF constant (H-B-2.5 vs H-S-1.0) showed comparable post-cracking behavior.

- At a fixed fiber dosage, the incorporation of FRCC, as a layer in the tension side only, yielded comparable toughness and maintained acceptable post-peak performance to counterpart specimens comprising FRCC over the full depth. This notion has proven 
to be technically more efficient and economic than the common practice of adding the fibers over the whole cross-section.

- The superior bonding of BF pellets with the cementitious matrix was one of the main reasons for such an enhanced post-cracking behavior compared to SF, which is promising to produce high strength and high ductility cementitious composites using non- metallic fibers.

- In comparison to $\mathrm{N}-\mathrm{X}-0.0$ and $\mathrm{H}-\mathrm{X}-0.0$, the pull-off test results showed that the bond strength of all fibrous composites, despite the type or dosage of the fibers included, increased. In addition, the bond strength for the later specimens were quite similar since the failure of the specimens occurred in the base concrete.

- Compared to the control specimens without SCMs ( $\mathrm{N}$ composites) and irrespective of the dosage of fibers, the passing charges of $\mathrm{H}$ composites were less than 1000 coulombs, which signified the synergistic effects of nano-silica and slag on densifying cementitious systems comprising different types of fibers and reducing their penetrability (as shown by the low penetration depth in the RCPT).

- Overall, the results showed the efficacy of developing a corrosion-free composite for improving the post-cracking behavior of specimens, as they successfully controlled the progress of cracks and behaved similarly to the samples cast with SF, which can be proposed as a promising solution for infrastructure applications such as bridge girders or overlays.

Author Contributions: Conceptualization, E.F.E.-S.; Data curation, A.B.; Formal analysis, A.B.; Investigation, A.B.; Methodology, A.B. and E.F.E.-S.; Project administration, E.F.E.-S.; Resources, E.F.E.-S.; Supervision, E.F.E.-S.; Validation, A.B.; Writing—original draft, A.B.; Writing—review and editing, E.F.E.-S. Both authors have read and agreed to the published version of the manuscript.

Funding: Natural Sciences and Engineering Research Council of Canada (NSERC) and the University of Manitoba Graduate Fellowship (UMGF).

Data Availability Statement: All data, models, and code generated or used during the study appear in the submitted article.

Acknowledgments: The authors wish to express their gratitude and sincere appreciation for the financial support received from the Natural Sciences and Engineering Research Council of Canada (NSERC) and the University of Manitoba Graduate Fellowship (UMGF). The IKO Construction Materials Testing Facility and Heavy Structures Laboratory at the University of Manitoba in which these experiments were conducted have been instrumental to this research.

Conflicts of Interest: The authors declare no conflict of interest.

\section{References}

1. Vasanelli, E.; Micelli, F.; Aiello, M.A.; Plizzari, G. Crack width prediction of FRC beams in short and long term bending condition. Mater. Struct. 2013, 47, 39-54. [CrossRef]

2. Nes, L.G.; Øverli, J.A. Structural behaviour of layered beams with fibre-reinforced LWAC and normal density concrete. Mater. Struct. 2015, 49, 689-703. [CrossRef]

3. Abousnina, R.; Alsalmi, H.I.; Manalo, A.; Allister, R.L.; Alajarmeh, O.; Ferdous, W.; Jlassi, K. Effect of short fibres in the mechanical properties of geopolymer mortar containing oil-Contaminated sand. Polymers 2021, 13, 3008. [CrossRef]

4. Bentur, A.; Mindess, S. Fiber Reinforced Cementitious Composites, 2nd ed.; E and FN Spon: New York, NY, USA, 2007.

5. Ferdous, W.; Manalo, A.; Siddique, R.; Mendis, P.; Zhuge, Y.; Wong, H.S.; Schubel, P. Recycling of landfill wastes (tyres, plastics and glass) in construction-A review on global waste generation, performance, application and future opportunities. Resour. Conserv. Recycl. 2021, 173, 105745. [CrossRef]

6. Cao, Y.; Li, P.; Brouwers, H.; Sluijsmans, M.; Yu, L. Enhancing flexural performance of ultra-high performance concrete by an optimized layered-structure concept. Compos. Part B Eng. 2019, 171, 154-165. [CrossRef]

7. Jiu-jun, Y.; Ran, H.; Yan-ling, D.; Ke-ru, W. Effects of the component and fiber gradient distributions on the strength of cementbased composite materials. J. Wuhan Univ. Technol. Mater. Sci. Educ. 2003, 18, 61-64. [CrossRef]

8. Iyer, P.; Kenno, S.Y.; Das, S. Mechanical properties of fiber reinforced concrete made with basalt filament fibers. J. Mater. Civ. Eng. ASCE 2015, 27, 04015015. [CrossRef]

9. Iyer, P.; Kenno, S.Y.; Das, S. Performance of fiber reinforced concrete made with basalt bundled fibers. Adv. Civ. Eng. Mater. 2016, 5, 107-123. [CrossRef] 
10. Arslan, M.E. Effects of basalt and glass chopped fibers addition on fracture energy and mechanical properties of ordinary concrete: CMOD measurement. Constr. Build. Mater. 2016, 114, 383-391. [CrossRef]

11. Ayub, T.; Shafiq, N.; Khan, S. Compressive stress-strain behavior of HSFRC reinforced with basalt fibers. J. Mater. Civ. Eng. ASCE 2016, 28, 06015014. [CrossRef]

12. Mahmoud, K.; Ghazy, A.; Bassuoni, M.T.; El-Salakawy, E. Properties of nanomodified fiber-reinforced cementitious composites. J. Mater. Civ. Eng. ASCE 2017, 29, 04017173. [CrossRef]

13. Banthia, N.; Zanotti, C.; Sappakittipakorn, M. Sustainable fiber reinforced concrete for repair applications. Constr. Build. Mater. 2014, 67, 405-412. [CrossRef]

14. Afroughsabet, V.; Ozbakkaloglu, T. Mechanical and durability properties of high strength concrete containing steel and polypropylene fibers. Constr. Build. Mater. 2015, 94, 73-82. [CrossRef]

15. Soylev, T.A.; Ozturan, T. Durability, physical and mechanical properties of fiber reinforced concretes at low-volume fraction. Constr. Build. Mater. 2014, 73, 67-75. [CrossRef]

16. Zheng, G.; Liu, J.; Li, M.; Zeng, Z.; Weng, C.; Yang, J. Effect of Polypropylene Fiber and Silica Fume on Mechanical Properties and Durability Improvement of High-Performance Concrete; CRC Press, Taylor and Francis Group: London, UK, 2015 ; pp. 333-342.

17. Zhang, M.; Islam, J.; Peethamparan, S. Use of nano-silica to increase early strength and reduce setting time of concretes with high volumes of slag. Cem. Concr. Compos. 2012, 34, 650-662. [CrossRef]

18. Malhotra, V.M.; Zhang, M.H.; Read, P.H.; Ryell, J. Long term mechanical properties and durability characteristics of highstrength/high-performance concrete incorporating supplementary cementing materials under outdoor exposure conditions. ACI Mater. J. 2000, 97, 518-525.

19. Said, A.M.; Zeidan, M.S.; Bassuoni, M.T.; Tian, Y. Properties of concrete incorporating nano-silica. Constr. Build. Mater. 2012, 36, 838-844. [CrossRef]

20. Kong, D.; Xiangfei, D.; Wei, S.; Zhang, H.; Yang, Y.; Shah, S.P. Influence of nano-silica agglomeration on microstructure and properties of the hardened cement-based materials. Constr. Build. Mater. 2012, 37, 707-715. [CrossRef]

21. Madani, H.; Bagheri, A.; Parhizkar, T. The pozzolanic reactivity of monodispersed nano-silica hydrosols and their influence on the hydration characteristics of portland cement. Cem. Concr. Res. 2012, 42, 1563-1570. [CrossRef]

22. CSA. Concrete Materials and Methods of Concrete Construction/Test Methods and Standard Practices for Concrete; CSA A23.1-19/A23.2-19; Can. Stand. Assoc. (CSA): Toronto, ON, Canada, 2019.

23. CSA. Cementitious Materials for Use in Concrete; CSA-A3001-13; CSA: Mississauga, ON, Canada, 2013.

24. ASTM. Standard Test Method for Sieve Analysis of Fine and Coarse Aggregates; C136; ASTM: West Conshohocken, PA, USA, 2014.

25. ASTM. Standard Test Method for Relative Density (Specific Gravity) and Absorption of Fine Aggregate; C128; ASTM: West Conshohocken, PA, USA, 2015.

26. ASTM. Standard Specification for Chemical Admixtures for Concrete; C494; ASTM: West Conshohocken, PA, USA, 2013.

27. Bediwy, A.G.; Bassuoni, M.T.; El-Salakawy, E.F. Residual Mechanical Properties of BPRCC under Cyclic Environmental Conditions. J. Mater. Civ. Eng. C 2021, 33, 04021290. [CrossRef]

28. ASTM. Standard Specification for Flow Table for Use in Tests of Hydraulic Cement; C230; ASTM: West Conshohocken, PA, USA, 2014.

29. ASTM. Standard Test Method for Flow of Hydraulic Cement Mortar; C1437; ASTM: West Conshohocken, PA, USA, 2015.

30. ASTM. Standard Test Method for Compressive Strength of Cylindrical Concrete Specimens; C39; ASTM: West Conshohocken, PA, USA, 2020.

31. ASTM. Standard Test Method for Tensile Strength of Concrete Surfaces and the Bond Strength or Tensile Strength of Concrete Repair and Overlay Materials by Direct Tension (Pull-Off Method); C1583; ASTM: West Conshohocken, PA, USA, 2020.

32. ASTM. Standard Test Method for Flexural Performance of Fiber-Reinforced Concrete (Using Beam with Third-Point Loading); C1609; ASTM: West Conshohocken, PA, USA, 2019.

33. ASTM. Standard Test Method for Electrical Indication of Concrete's Ability to Resist Chloride Ion Penetration; C1202; ASTM: West Conshohocken, PA, USA, 2019.

34. Bassuoni, M.T.; Nehdi, M.L.; Greenough, T.R. Enhancing the reliability of evaluating chloride ingress in concrete using the ASTM C1202 rapid chloride penetrability test. J. ASTM Int. 2006, 3, 1-13.

35. Hunger, M. An Integral Design Concept for Ecological Self-Compacting Concrete. Ph.D. Thesis, Eindhoven University of Technology, Eindhoven, The Netherlands, 2010.

36. Chesner, W.H.; Collins, R.J.; MacKay, M.H.; Emery, J. User Guidelines for Waste and By-Product Materials in Pavement Construction; No. FHWA-RD-97-148, Guideline Manual, Rept No. 480017; Recycled Materials Resource Center, University of Wisconsin: Madison, WI, USA, 2002.

37. Ranjbar, N.; Mehrali, M.; Mehrali, M.; Alengaram, U.J.; Jumaat, M.Z. High tensile strength fly ash based geopolymer composite using copper coated micro steel fiber. Constr. Build. Mater. 2016, 112, 629-638. [CrossRef]

38. Yu, R.; Spiesz, P.; Brouwers, H.J.H. Development of ultra-high performance fibre reinforced concrete (UHPFRC): Towards an efficient utilization of binders and fibres. Constr. Build. Mater. 2015, 79, 273-282. [CrossRef]

39. Wu, Z.; Shi, C.; He, W.; Wu, L. Effects of steel fiber content and shape on mechanical properties of ultra high performance concrete. Constr. Build. Mater. 2016, 103, 8-14. [CrossRef]

40. Montgomery, D.C. Design and Analysis of Experiments; Wiley: New York, NY, USA, 2017.

41. Puertas, F.; Amat, T.; Fernández-Jiménez, A.; Vázquez, T. Mechanical and durable behaviour of alkaline cement mortars reinforced with polypropylene fibres. Cem. Concr. Res. 2003, 33, 2031-2036. [CrossRef] 
42. Zhang, Z.H.; Yao, X.; Zhu, H.J.; Hua, S.D.; Chen, Y. Preparation and mechanical properties of polypropylene fiber reinforced calcined kaolin-fly ash based geopolymer. J. Cent. South Univ. 2009, 16, 49-52. [CrossRef]

43. Branston, J.; Das, S.; Kenno, S.Y.; Taylor, C. Mechanical behaviour of basalt fibre reinforced concrete. Constr. Build. Mater. 2016, 124, 878-886. [CrossRef]

44. Hsu, L.S.; Hsu, C.T. Stress-strain behavior of steel-fiber high-strength concrete under compression. Struct. J. 1994, 91, 448-457.

45. Behfarnia, K.; Salemi, N. The effects of nano-silica and nano-alumina on frost resistance of normal concrete. Constr. Build. Mater. 2013, 48, 580-584. [CrossRef]

46. ACI Committee 363. Report on High-Strength Concrete; Report No. 363R-10, March; American Concrete Institute: Farmington Hills, MI, USA, 2010.

47. Li, V.C.; Leung, C.Y. Steady state and multiple cracking of short random fiber composites. J. Eng. Mech. 1992, 118, $2246-2264$. [CrossRef]

48. CSA. Canadian Highway Bridge Design Code and Commentary; CSA S6-19; Can. Stand. Assoc. (CSA): Toronto, ON, Canada, 2019.

49. Ghazy, A.; Bassuoni, M.T.; Maguire, E.; O’Loan, M. Properties of fiber-reinforced mortars incorporating nano-silica. Fibers 2016, 4, 6. [CrossRef]

50. Hossain, K.M.A.; Lachemi, M.; Sammour, M.; Sonebi, M. Strength and fracture energy characteristics of self-consolidating concrete incorporating polyvinyl alcohol, steel and hybrid fibres. Constr. Build. Mater. 2013, 45, 20-29. [CrossRef] 